University of Nebraska - Lincoln

DigitalCommons@University of Nebraska - Lincoln

U.S. Department of Veterans Affairs Staff

Publications

U.S. Department of Veterans Affairs

2005

\title{
The Irbesartan in Heart Failure With Preserved Systolic Function (I-PRESERVE) Trial: Rationale and Design
}

\author{
Peter Carson \\ Georgetown University Hospital \\ Barry M. Massie \\ University of California - San Francisco, barry.massie@va.gov \\ Robert Mckelvie \\ McMaster University, robert.mckelvie@phri.ca \\ John Mcmurray \\ University of Glasgow, John.McMurray@glasgow.ac.uk \\ Michel Komajda \\ Pitie-Salpetriere Hospital, michel.komajda@psl.aphp.fr \\ See next page for additional authors
}

Follow this and additional works at: https://digitalcommons.unl.edu/veterans

Carson, Peter; Massie, Barry M.; Mckelvie, Robert; Mcmurray, John; Komajda, Michel; Zile, Michael; Ptaszynska, Agata; and Frangin, Gerald, "The Irbesartan in Heart Failure With Preserved Systolic Function (I-PRESERVE) Trial: Rationale and Design" (2005). U.S. Department of Veterans Affairs Staff Publications. 47.

https://digitalcommons.unl.edu/veterans/47

This Article is brought to you for free and open access by the U.S. Department of Veterans Affairs at DigitalCommons@University of Nebraska - Lincoln. It has been accepted for inclusion in U.S. Department of Veterans Affairs Staff Publications by an authorized administrator of DigitalCommons@University of Nebraska - Lincoln. 


\section{Authors}

Peter Carson, Barry M. Massie, Robert Mckelvie, John Mcmurray, Michel Komajda, Michael Zile, Agata Ptaszynska, and Gerald Frangin 


\title{
Clinical Trials Methods and Design
}

\section{The Irbesartan in Heart Failure With Preserved Systolic Function (I-PRESERVE) Trial: Rationale and Design}

\author{
PETER CARSON, MD, ${ }^{1}$ BARRY M. MASSIE, MD, ${ }^{2}$ ROBERT MCKELVIE, MD, PhD,${ }^{3}$ JOHN MCMURRAY, MD,${ }^{4}$ \\ MICHEL KOMAJDA, MD, ${ }^{5}$ MICHAEL ZILE, MD ${ }^{6}$ AGATA PTASZYNSKA, MD, ${ }^{7}$ AND GERALD FRANGIN, MD, ${ }^{8}$ \\ FOR THE I-PRESERVE INVESTIGATORS \\ Washington, DC; San Francisco, California, Hamilton, Ontario, Canada; Glasgow, Scotland; Paris, France; \\ Charleston, South Carolina; Princeton, New Jersey; Montpellier, France
}

\begin{abstract}
Background: Although $40 \%$ to $50 \%$ of patients with chronic heart failure (HF) have relatively preserved systolic function (PSF), few trials have been conducted in this population and treatment guidelines do not include evidence-based recommendations.

Methods and Results: The Irbesartan in Heart Failure with Preserved Systolic Function (I-PRESERVE) is enrolling 4100 subjects with HF-PSF to evaluate whether $300 \mathrm{mg}$ irbesartan is superior to placebo in reducing mortality and prespecified categories of cardiovascular hospitalizations. The principal inclusion criteria are age $\geq 60$ years, heart failure symptoms, an ejection fraction $\geq 45 \%$, and either hospitalization for heart failure within 6 months or corroborative evidence of heart failure or the substrate for diastolic heart failure. Additional secondary end points include cardiovascular mortality, cause-specific mortality and morbidity, change in New York Heart Association functional class, quality of life, and N-terminal pro-BNP measurements. Follow-up will continue until 1440 patients experience a primary end point. Substudies will evaluate changes in echocardiographic measurements and serum collagen markers.

Conclusion: I-PRESERVE is the largest trial in this understudied area and will provide crucial information on the characteristics and course of the syndrome, as well as the efficacy of the angiotensin receptor blocker irbesartan.
\end{abstract}

Key Words: $\mathrm{AT}_{1}$-receptor blockers, ACE inhibition, Left ventricular function, Congestive heart failure.

From the ${ }^{1}$ Department of Veterans Affairs Medical Center, Georgetown University Hospital, Washington, DC; ${ }^{2}$ University of California, San Francisco and the San Francisco VAMC, San Francisco, CA; ${ }^{3}$ Hamilton Health Sciences, McMaster University, Hamilton, Ontario, Canada; ${ }^{4}$ CRI in Heart Failure, University of Glasgow, Scotland, UK; ${ }^{5}$ Department of Cardiology, Pitié-Salpêtrière Hospital, Paris, France: ${ }^{6}$ Cardiology Division, Medical University of South Carolina, Charleston, SC; ${ }^{7}$ Pharmaceutical Research Institute, Bristol-Myers Squibb, Princeton, NJ; ${ }^{8}$ Sanofi Synthelabo Recherche, Montpellier, France.

Manuscript received March 17, 2005; revised manuscript received May 20, 2005; revised manuscript accepted June 2, 2005.

Reprint requests: Peter E. Carson, MD, VAMC Chief, MICU, 50 Irving Street, Washington, DC 20420.

All decisions regarding this manuscript were made by a guest editor. This study is supported by Bristol-Myers Squibb and Sanofi-Aventis. Drs. Carson, Massie, McKelvie, McMurray, Komajda, and Zile receive research support and consultant fees from Bristol Myers Squibb and Sanofi Aventis. Drs. Ptaszynska and Frangin are employees of Bristol-Myers Squibb and Sanofi Aventis, respectively.

1071-9164/\$ - see front matter

(c) 2005 Elsevier Inc. All rights reserved.

doi:10.1016/j.cardfail.2005.06.432
Chronic heart failure (CHF) is a major and growing cause of cardiovascular morbidity and mortality in patients throughout the world. ${ }^{1}$ Previously, it had often been assumed that most CHF patients have underlying systolic dysfunction, which is responsible for their clinical presentation. However, it has become increasingly apparent over the last decade that many heart failure patients have a normal or nearly normal ejection fraction-described as heart failure with preserved systolic function (HF-PSF). ${ }^{2,3}$ Database reviews report a prevalence ranging from $40 \%$ to $71 \% .{ }^{4}$ For example, the Framingham Heart Study reported a $51 \%$ prevalence of HF-PSF (defined as a left ventricular ejection fraction $[\mathrm{LVEF}] \geq 50 \%)^{5}$ whereas the Cardiovascular Health Study reported 55\% of existing heart failure subjects with HF-PSF (LVEF $>50 \%$ ). ${ }^{6}$ More recently, the EuroHeart Failure Survey noted that among patients enrolled after hospitalization for heart failure, $49 \%$ of men and $72 \%$ of women had an LVEF of $40 \%$ or more. ${ }^{7}$ In addition, the Acute Decompensated Heart Failure National 
Registry (ie, ADHERE) reported that in acute decompensated HF patients with documented measurement of LVEF, fully $51 \%$ of patients had preserved systolic function (LVEF $\geq 0.40)^{8}$

Although these data consistently indicate that HF-PSF is a problem of significant clinical magnitude, few clinical trials have been conducted in this specific patient population and there is no proven therapy. As a result, without evidence-based recommendations, guideline groups such as the European Society of Cardiology currently suggest that HF-PSF be treated with $\beta$-blockers, verapamil-type calcium antagonists, angiotensin-converting enzyme (ACE) inhibitors, or diuretics, based only on specific patient comorbid conditions. ${ }^{9}$ In clinical practice, medical treatment has been largely empiric.

The widespread role of the renin-angiotensin system (RAS) in cardiovascular disease, particularly in systolic heart failure, has led to investigation of RAS inhibitors in HF-PSF. Specifically the angiotensin receptor blockers (ARBs) have been of interest because of their ability to more completely antagonize the effects of angiotensin II and their excellent tolerability. The only prospective outcome trial in HF-PSF, the recently completed CHARMPRESERVED study, ${ }^{10}$ reported results that suggested a promising role for ARBs in HF-PSF, although these results cannot be seen as conclusive.

The Irbesartan in Heart Failure with Preserved Systolic Function (I-PRESERVE) trial, the largest trial in this understudied area, was designed to definitively test the hypothesis that an ARB, irbesartan, would improve clinical outcomes in patients with HF-PSF. The purpose of this article is to describe the protocol and processes that will be used to collect data and to test the hypothesis of the trial.

\section{Design of the I-PRESERVE Trial}

\section{Objectives}

The objectives of I-PRESERVE trial are to study the effects of irbesartan on morbidity and mortality outcomes, symptom scores, and quality of life in a patient population with heart failure and preserved systolic function.

\section{Study Population}

Specific inclusion criteria are listed in Table 1. These inclusion criteria were designed to enroll a patient population similar to that observed in epidemiologic and communitybased studies, with ongoing heart failure symptoms and an increased likelihood of clinical events. Thus the requirement for age $\geq 60$ years, LVEF $\geq 45 \%$, and recent hospitalization for heart failure or moderate to severe symptoms and corroborative objective evidence of heart failure or a cardiac substrate for diastolic dysfunction were required for the study.

The exclusion criteria are shown in Table 2. These were designed to exclude patients with confounding medical conditions or an inability to meaningfully participate in the trial.

Table 1. Key Inclusion Criteria for Patients in the I-PRESERVE Study

Male or female of age $\geq 60$ years

Left ventricular ejection fraction (LVEF) $\geq 45 \%$

Willing to provide written informed consent

Current heart failure symptoms consistent with New York Heart Association (NYHA) Class II or higher as specified as follows:

Hospitalization for heart failure within the last 6 months and currently symptoms of NYHA II-IV

or

Currently symptoms of NYHA
III-IV and corroborative
evidence (at least 1 of the
following):
Chest $\mathrm{x}$-ray evidence of
pulmonary congestion
ECG evidence of moderate
or severe $\mathrm{LVH}$ (at least 1 of
the following):
$\mathrm{SV}_{1}+\mathrm{RV}_{5}$ or $\mathrm{RV}_{6}>3.5 \mathrm{mV}$
$(35 \mathrm{~mm}$ at normal standard)
RaVL $>1.1 \mathrm{mV}(11$ mm at
normal standard)
RaVL $+\mathrm{SV} 3>2.8 \mathrm{mV}$ in
men or $2.0 \mathrm{mV}$ in women
( $28 \mathrm{~mm}$ and $20 \mathrm{~mm}$ at
normal standard,
respectively)
LBBB on ECG
Echocardiographic evidence
of any 1 of the following:
LVH (PW + IVS thickness)/
$2 \geq 1.3 \mathrm{~cm}$ or posterior wall
thickness $\geq 1.2 \mathrm{~cm}$
Enlarged left atrium (LA) in
the absence of atrial
fibrillation:
women $\geq 42 \mathrm{~mm}$
men $\geq 46 \mathrm{~mm}$

ECG, electrocardiogram; LBBB, left bundle-branch block; LVH, left ventricular hypertrophy.

\section{Study Design}

I-PRESERVE is a placebo-controlled, double-blind, multicenter, international, parallel-group study. Figure 1 summarizes the study design. Subjects are randomized according to a 1:1 ratio of irbesartan to placebo, stratified by site and by use of ACE inhibitors at baseline, using an automated, central randomization system. ACE inhibitor use is limited to those patients with a specific indication other than hypertension (such as diabetes mellitus with complications and significant coronary or peripheral artery disease), In addition, only one third of patients at each site are permitted to be randomized with ACE inhibitor concomitant therapy.

This study will be conducted according to the ethical principles described in the Declaration of Helsinki and will have received Institutional Review Board/Independent Ethics Committee approval before initiation. Freely given written informed consent must be obtained from every subject before trial participation.

\section{Study Endpoints}

The primary end point is defined as time from randomization to the first occurrence of the composite outcome of 
Table 2. Key Exclusion Criteria for Patients in the I-PRESERVE Study

Evidence of primary hypertrophic or restrictive cardiomyopathy or systemic illness known to be associated with infiltrative heart disease

Cor pulmonale or other causes of right heart failure not related to left ventricular dysfunction

Pericardial constriction

Life-threatening or uncontrolled dysrhythmia including atrial fibrillation with a resting ventricular rate $>120$ beats per minute

Subjects with an implantable cardioverter-defibrillator that has discharged in the past 3 months

Stroke or cerebrovascular surgery within 3 months

Clinically significant pulmonary disease, as evidenced by prior mechanical assisted ventilation, hospitalizations, or use of oral corticosteroids for pulmonary decompensation within 12 months, requirement of home oxygen or significant pulmonary fibrosis

Sitting systolic BP $<100 \mathrm{~mm} \mathrm{Hg}$

Sitting systolic BP $>160 \mathrm{~mm} \mathrm{Hg}$ or diastolic BP $>95 \mathrm{~mm} \mathrm{Hg}$ despite therapy with antihypertensive medications other than the study drug

Known systemic diseases that may limit life expectancy to $<3$ years or are likely to result in hospitalization within the next 6 months

Significant laboratory abnormalities, such as hemoglobin $<11 \mathrm{mg} / \mathrm{dL}$, creatinine $>2.5 \mathrm{mg} / \mathrm{dL}$, AST or ALT $>3 \times$ upper limit of normal

Clinical evidence of uncontrolled hyperthyroidism or hypothyroidism

Known or suspected bilateral renal artery stenosis

Any patient characteristic that may interfere with compliance

Participation in any study of an investigational drug

death (all cause) or cardiovascular hospitalization. Cardiovascular hospitalizations are defined as:

Protocol specified cardiovascular hospitalizations for a primary cause of: worsening heart failure, unstable angina, myocardial infarction, ventricular dysrhythmia, atrial dysrhythmia, or stroke.

The endpoint additionally includes myocardial infarction or stroke occurring during any hospitalization at any point during the study.

Secondary endpoints include the effect of irbesartan as compared with placebo in reducing the risk of: cardiovascular death; all-cause mortality; combined vascular endpoint: cardiovascular death, nonfatal myocardial infarction (MI) or nonfatal stroke; or combined HF endpoint: HF mortality or hospitalizations; the effect of irbesartan as compared with placebo on: quality of life as measured by the Minnesota Living with Heart Failure questionnaire, change in New York Heart Association (NYHA) functional class, change in patient global assessment of symptoms, N-terminal B-type natriuretic peptide levels in blood.

\section{Sample Size and Statistical Plan}

The trial was designed to provide $90 \%$ power to detect a $14.5 \%$ reduction in the primary event rate with a 2 -sided type I error rate of 0.05 , which would require a total of 1440 patients to experience a first, primary event. The sample size was estimated based on data from the placebo group in the Digitalis Investigation Group ancillary trial in which 998 patients with LVEF $>45 \%$ were followed for a mean of 36 months. Using similar endpoints, an annual primary event rate (death of any cause or cardiovascular hospitalizations) of $18 \%$ was estimated for the placebo group. With this projected event rate, a sample size of at least 3600 subjects with 2 years of uniform recruitment and a minimum follow-up of 2 years was anticipated to attain 1440 primary events. By the second year of the study, it became apparent that the total event rate was lower than projected. As a result, in April 2004, the I-PRESERVE Executive Committee recommended an increase in the sample size to 4100 patients to reach the requisite 1440 events within the initial projected timeline.

The primary end point and secondary end points based on clinical outcomes will be analyzed based on the time to the first occurrence. Survival curves by treatment will be estimated using the Kaplan-Meier procedure and compared using a 2-sided log-rank test. The treatment effect will be modeled using Cox proportional hazards models and adjusted relative risks will be estimated from them.

\section{Substudies}

Two formal substudies are being conducted by selected I-PRESERVE sites:

\section{IRBESARTAN}

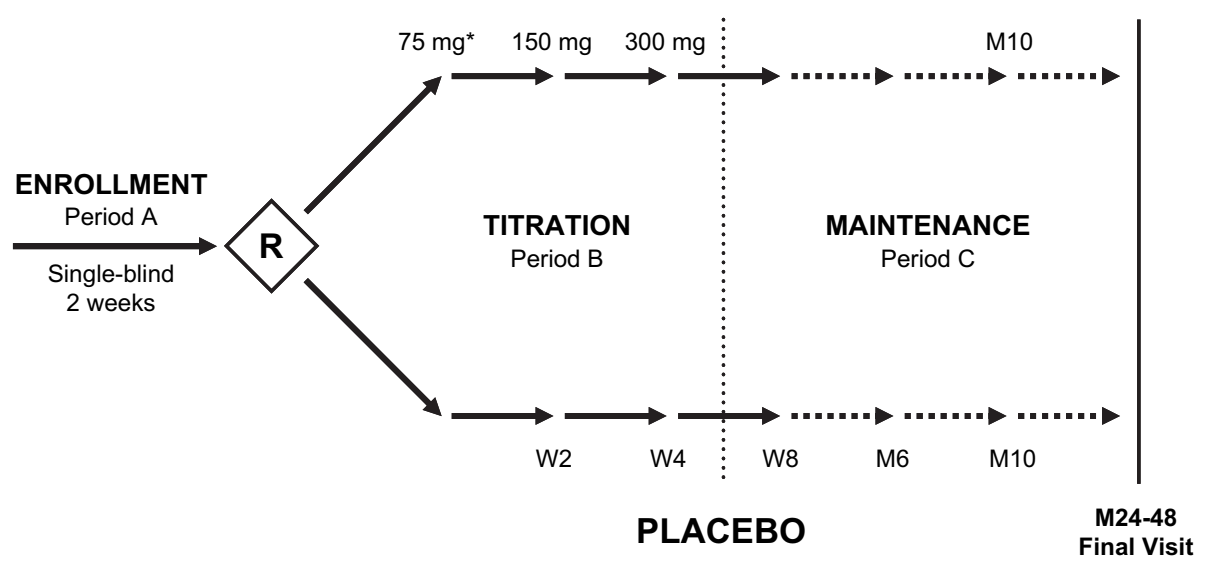

Fig. 1. I-PRESERVE trial design. $r=1: 1$ central randomization; $*=$ Forced titration 
1. Echocardiography-few data exist on left ventricular size and function in HF-HSF. This substudy will use sequential echo Doppler imaging at baseline and month 10 to assess a number of parameters associated with diastolic function. The primary hypothesis is that treatment with irbesartan results in improvement in left atrial area. Secondary objectives are measurement change in Epk/Ea and in LV mass index, description of baseline LV size and function, and assessment of the relationship between LA size and the primary clinical outcome. The design will enroll 624 subjects to yield 500 evaluable echo studies.

2. Collagen markers - collagen markers have been noted to be elevated in heart failure, although no data exist in HF-PSF. This study will measure peripheral collagen markers, pro-collagen Type III and osteopontin, at baseline and 6 months. The primary objective will be to compare change in pro-collagen Type III between irbesartan and placebo. Secondary objectives will measure differences in treatment groups with collagen markers and the relation of baseline values to the primary clinical outcome. The study is designed for enrollment of 312 subjects to yield at least 200 samples.

\section{Organization}

The I-PRESERVE Executive Committee includes 2 coprincipal investigators and 4 other members-all of whom are cardiologists. The committee receives operational assistance from representatives of the sponsoring companies, Bristol-Myers Squibb and Sanofi-Aventis, who are exofficio members. The Executive Committee was responsible for the development of the study protocol and amendments and overseeing the conduct of the trial. The Executive Committee also functions as the Publication Committee for this trial. A Steering Committee, consisting of the Executive Committee plus the national coordinators from the participating countries, provides additional scientific input to the Executive Committee and guidance on the logistics of the study. An End-Point Adjudication Committee reviews all clinical events during the trial and adjudicates all study endpoints. The Endpoint Committee chair is a member of the Executive Committee.

The Data Safety Monitoring Board is independent of the study committees and operational teams. At least 2 interim evaluations of all-cause mortality are planned and will use predefined stopping rules for major safety concerns.

\section{Discussion}

Despite the growing importance of HF-PSF, this remains an understudied area. The paucity of clinical trials in HFPSF reflects a number of factors, including the relatively recent recognition of the existence and importance of this condition, disagreement concerning its pathophysiology as well as lack of a simple and straightforward diagnostic test. However, our understanding of the syndrome is increasing, and there is growing evidence that most patients with this presentation have underlying left ventricular diastolic dysfunction. Recent mechanistic studies in patients with heart failure and LVEF $>50 \%$, in whom other etiologies such as valvular, pericardial disease, and high output states have been excluded, indicate that there are demonstrable abnormalities of diastolic function-particularly impaired relaxation or reduced left ventricular compliance. ${ }^{11,12}$ Echocardiographic abnormalities, such as abnormalities of mitral valve flow and annular velocities, pulmonary venous flow, pulmonary artery pressures, and left atrial size are usually present, although they are not specific for diastolic dysfunction. Elevated natriuretic peptide levels are also often present, although these are also not specific for this diagnosis.

Epidemiologic and cohort studies provide consistent information about the characteristics of patients of patients with HF-PSF. ${ }^{3-6}$ These patients are generally older than those with systolic dysfunction and much more likely to be women. The majority have a history of hypertension, which often persists after the development of heart failure. Although many may have underlying coronary disease, previous myocardial infarction is far less common than in patients with systolic dysfunction. These characteristics are consistent with the importance of left ventricular hypertrophy and "aging myocardium" (presbycardia) as mechanisms of diastolic dysfunction. Although mechanistic studies, as discussed previously, demonstrate that abnormalities of diastolic function are invariably present in HFPSF patients, reviews of larger less-controlled databases have noted that indices of diastolic function are also frequently abnormal in elderly patients who are without symptoms and also note the high rate of comorbidites. ${ }^{4}$ There is, then, disagreement concerning the relative contribution of diastolic dysfunction to heart failure in a population prone to other comorbidities. Therefore, unlike in systolic heart failure, in which the concepts linking systolic dysfunction and remodeling to the development and progression of the syndrome are increasingly understood and accepted, there is still controversy about the development and progression of HF-PSF. However, as in systolic heart failure, preclinical and clinical evidence suggest that the RAS is a contributing factor in the development of HF-PSFprincipally through the trophic effects of angiotensin II in the vasculature and myocardium, but perhaps also through myocardial fibrosis mediated by aldosterone. ${ }^{13,14}$ Although several animal models of diastolic dysfunction have been available, only recently has an animal model of HF-PSF become available: Dahl salt-sensitive rats fed a high salt diet beginning at 7 weeks developed high blood pressure, compensated left ventricular hypertrophy (LVH), and later transitioned into HF-PSF. Unlike previous models, these animals developed heart failure in the absence of systolic dysfunction. In these rats, treatment with an ARB blocked the progression to LVH and transition into HF-PSF. ${ }^{15}$

Clinical trials investigating the effects of RAS inhibition, using either ACE inhibitors or ARBs, in HF-PSF are still 
limited but increasing. Several small studies provided the first evidence that these agents may be effective in this setting. A retrospective analysis of Vasodilator Heart Failure Trial (ie, V-HeFT) I and II for LVEF $>35 \%$ patients (mean LVEF 46\%) suggested benefit for the ACE inhibitor enalapril. ${ }^{16}$ In a placebo-controlled crossover study, the ARB losartan was shown to increase exercise tolerance and improve quality of life in subjects with diastolic dysfunction and a hypertensive response to exercise. ${ }^{17}$ Finally, in an outcomes trial, CHARM-PRESERVED, the ARB candesartan reduced hospitalizations for HF, but did not significantly reduce the primary composite endpoint of cardiovascular death or HF hospitalization. ${ }^{10}$ Thus, although there is a strong mechanistic rationale for further investigation of RAS inhibitors in this clinical syndrome, there remains a lack of clinical data upon which to base guidelines for the use of these agents in treatment of HF-PSF.

The ARB irbesartan was felt to be particularly appropriate for this trial because, besides being a potent and well-tolerated antihypertensive agent, it has proven to be effective in reversing LVH in the Swedish Irbesartan Left Ventricular Hypertrophy Investigation versus Atenolol (ie, SILVHIA) trial ${ }^{18}$ and it also reduced the occurrence of CHF compared with both placebo and amlodipine in Irbesartan Diabetic Nephropathy Trial (ie, IDNT). ${ }^{19}$

I-PRESERVE was designed to test a RAS inhibitor in a patient population that closely matched the HF-PSF populations described in databases. Because older patients predominate in these databases, I-PRESERVE targeted an older population by excluding patients younger than age 60 . The LVEF lower limit criterion was also crucial for a protocol in this area. As noted previously, at the time of design of I-PRESERVE, few clinical trial data existed for heart failure with an ejection fraction higher than $40 \%$. However, available evidence- such as in the Duke database ${ }^{20}$ (HF-PSF patients selected to undergo cardiac catheterization) with a mean LVEF of 54\% - suggested that the usual LVEF in this syndrome was considerably higher than this level. To best typify the population, and to study patients without systolic heart failure, a minimum ejection fraction of $45 \%$ was chosen. The protocol also excluded patients with previous systolic dysfunction, such as those that had an increased ejection fraction during $\beta$-blocker therapy or following revascularization, because these patients are likely to be pathophysiologically distinct from other HF-PSF patients.

Unlike systolic dysfunction, with a lower LVEF, HF-PSF does not have an easily ascertained diagnostic marker. Noninvasive measurements of diastolic function have been controversial, but, moreover, are not easily obtained in a large international clinical trial. Although only partially available during the design of I-PRESERVE, the data by Zile and colleagues, discussed previously, confirm that selected patients with HF-PSF invariably have echocardiographic and hemodynamic abnormalities of diastolic dysfunction. ${ }^{11,12}$ These important findings indicate that it is not necessary to routinely measure invasive indices of diastolic function in patients with clinical symptoms and signs of
HF-PSF to establish that diastolic heart failure is present. To strengthen the diagnosis of heart failure, I-PRESERVE does require additional clinical criteria for entry which can take 1 of 2 pathways: continuing NYHA II-IV symptoms at enrollment and a heart failure hospitalization within 6 months or continuing NYHA III-IV symptoms, with objective indication of decompensation (chest x-ray), or evidence suggesting a structural basis of diastolic dysfunction (echocardiographic or electrocardiographic evidence). The former pathway, with less advanced symptoms, adds the hospitalization criterion to improve diagnostic accuracy but also to enhance the event rate, because previous data suggest that patients hospitalized for heart failure will likely be hospitalized again within 6 months. ${ }^{21}$ The latter pathway requires a higher level of symptoms and also adds structural features suggesting diastolic dysfunction. It is worth noting that the CHARM-PRESERVED protocol did not require either a HF hospitalization or structural criteria for entry. ${ }^{22}$

The primary composite endpoint for I-PRESERVE is allcause mortality or protocol-specified cardiovascular hospitalization, analyzed as time to first event. This inclusive endpoint was selected because it optimally reflects the outcomes of this patient population. Although heart failure may be the cause of initial presentation, available data suggest that the minority of cardiovascular events that occur in this population are primarily attributable to heart failure. At the time of trial design, the available clinical trial data, the Digitalis Investigation Group study reported that $60 \%$ of hospitalizations had a primary cardiovascular cause, whereas only $20 \%$ were primarily from heart failure. ${ }^{23}$ More recently the CHARM Preserved investigators have reported similar data. ${ }^{10}$ The I-PRESERVE protocol stipulates specific cardiovascular categories of hospitalization that represented potentially realistic targets for therapy: heart failure, unstable angina, myocardial infarction, atrial arrhythmias, and ventricular arrhythmias. Documented myocardial infarction and stroke occurring at any time during the trial are also included as primary end points as they represent irreversible events. The protocol also stipulates that a primary end point hospitalization would require an overnight duration and either parenteral or augmented oral therapy for the prespecified cardiovascular condition.

Because there is no proven therapy for HF-PSF, there is also no obvious mandated therapy. However, patients with HF-PSF are likely to have other comorbidities and require treatment for conditions such as hypertension, coronary artery disease, and atrial fibrillation. Accordingly, because background treatment for these conditions would need to be allowed, only ARB treatment would be an absolute exclusion. However, because there is significant pharmacologic overlap with ARBs, ACE inhibitor therapy was restricted to patients who had a specific indication for these agents, such as diabetic nephropathy or advanced atherosclerotic disease including confirmed myocardial or cerebrovascular infarctions. Entry of patients requiring ongoing use of an ACE inhibitor was limited to one third of 
the population, because I-PRESERVE was not intended to be a trial of combination ARB and ACE-inhibitor therapy. This level of ACE inhibitor usage was also consistent with that observed in community practice at the time I-PRESERVE was designed.

An important feature of I-PRESERVE concerns natriuretic peptides. Brain natriuretic peptides (BNP) have been noted to be elevated in diastolic heart failure, but observations are limited. Largely for this reason, BNP measurement in any form is not an entry criteria in this study: however, pro-BNP will be measured in all patients at baseline and at 2 points of follow-up. This will be the largest dataset of natriuretic peptides in HF-PSF, and I-PRESERVE will provide strong evidence for the range of values for pro-BNP occurring in this syndrome. Because recent data with BNP in systolic heart failure supports a strong prognostic role, ${ }^{24}$ the relation pro-BNP to clinical events in I-PRESERVE will of great interest. Finally, the trial design will assess the effect of irbesartan treatment on proBNP levels.

\section{Conclusion}

HF-PSF represents a large part of the overall morbidity and mortality burden of chronic heart failure. It is the predominant form of heart failure in the elderly and in women. The I-PRESERVE protocol, the largest HF-PSF study to date, is designed to examine the prognosis and response to irbesartan in an understudied and poorly understood area.

\section{Acknowledgments}

The I-PRESERVE Executive Committee members are: Peter Carson (USA), Barry M. Massie (USA) (cochairs), Robert McKelvie (Canada), John McMurray (UK), Michel Komajda (France), Michael Zile (USA). Ex officio members are: Agata Ptaszynska (BMS), Gerald Frangin (Sanofi).

The I-PRESERVE Steering Committee comprises: Dennis V. Cokkinos (Greece), J.M. Cornel (The Netherlands), Ulf Dahlström (Sweden), Anthony Dalby (South Africa), Rafael Diaz (Argentina), Carlos Jerjes Sanchez Diaz (Mexico), Ranier Dietz (Berlin), Istvén Édes (Hungary), Ferenc Follath (Switzerland), Ricardo Seabra Gomes (Portugal), J.R. González-Juanatey (Spain), Jaromir Hradec (Czech Republic), Yves Juilliere (France), Lars Kober (Denmark), Dalane William Kitzman (USA), Henry Krum (Australia), V. Mareev (Russia), Theresa McDonagh (UK), Ken McDonald (Ireland), Evandro Tinoco Mesquita (Brazil), Christopher M. O'Connor (USA), Jan-Erik Otterstad (Norway), Piotr Ponikowski (Poland), Jean-Lucien Rouleau (Canada), L. Tavazzi (Italy), and Johan Vanhaecke (Belgium).

The Data Safety Monitoring Board consists of Sidney Goldstein (USA) (chair), Jay Cohn (USA), Desmond Julian (UK), Alain Leizorovicz (France), and James Neaton (USA).
The End-point Adjudication Committee is chaired by Michael Zile (USA) and includes: Michael White (Canada), William Gaasch (USA), Markus Haass (Germany), William Little (USA), Jose Lopez-Sendon (Spain), Inder Anand (USA), Alan Miller (USA), and John Teerlink (USA).].

\section{Appendix: The I-PRESERVE Trial Investigators Included the Following}

\section{Argentina}

R. Diaz (National Coordinator); PIs: A. Fernandez (Sanatorio Modelo de Quilmes), A. Ahuad Guerrero (Corporación Médica General San Martín), A. Hershon (Fundación Favaloro), E. Kuschnir (Instituto del Corazón Clínica Sucre), E. Marzetti (Hospital Luis Lagomaggiore), D. Nul (Clínica Constituyentes), E. Perna (Instit de Card de Corrientes Jf Cabral), E. Paolasso (Instituto de Investigaciones Clinicas de Rosario).

\section{Australia}

H. Krum (National Coordinator); PIs: J. Amerena (Geelong Hospital), D. Colquhoun (Wesley Medical Center), D. Cross (Royal Brisbane \& Womens Hospital), I. Jeffery (The Canberra Hospital), H. Krum (Alfred Hospital), T. Marwick (Princess Alexandra Hospital), D. Rees (St. George Hospital), A. Sindone (Concord Repatriation General Hospital), B. Singh (Launceston General Hospital), J. Waites (Coffs Harbour Health Campus), W. Walsh (Prince of Wales Hospital).

\section{Belgium}

J. Vanhaecke (National Coordinator); PIs: J. Boutefeu (Hospital Princesse Paola), G. Boxho (Ch La Tourelle), F. Coucke (Algemeen Ziekenhius St. Erasmus), E. El Allaf (C.H. Hutois), R. Geukens (Paaz Virga Jesse Ziekenhuis), T. Gillebert (Universitair Ziekenhuis Gent), M. Goethals (O.L. Vrouwziekenhuis), W. Van Mieghem (Ziekenhuis Oost-Limburg Campus Andre Dumont), J. Vanhaecke (Universitair Ziekenhuis Leuven Gasthuisberg).

\section{Brazil}

E. Mesquita (National Coordinator); PIs: D. Albuquerque (Hops Univ Pedro Ernesto - UERJ), A. DePaola (Univ Federal de Sao Paolo), G. Feitosa (Hospital Santa Isabel), J.F. Kerr Saraiva (Hosp Celso Piero Da Puccamp), E. Mesquita (Hospital Pro-Cardiaco), M. Moreira (Hospital Felicio Rocho), S. Rassi (Hosp Das Clinicas Da UFG), S. Salles Xavier (Hos Uni Clementino Fraga Filho).

\section{Canada}

J. Rouleau (National Coordinator); PIs: C. Constance (Hopital Masonneuve-Rosemont), E. Davies (Scarborough General Hospital), C. Fortin (Neufort, Inc.), P. Harvey (University Health Network), D. Isaac (Univeristy of Calgary), P. Klinke (Victoria Heart Institute Foundation), K. Kwok (Etobicoke Cardiology Assoc.), R. Leader (Baywood 
Medical Center), P. Ma (Heart Health Institute), R. McKelvie (Hamilton General Hospital), G. Moe (St. Michael's Hospital), A. Mukherjee (Digital Cardiology), J. Parker (Mount Sinai Hospital), G. Proulx (Hospial Laval), D. Savard (Medi Recherche), F. St-Maurice (Viacar Recherche Clinique), L. Yao (Humber River Regional Hospital).

\section{Czech Rep.}

J. Hradec (National Coordinator); PIs: J. Drazka (Masarykova Nemocnice), P. Fridl (Institut Klinicke A Expermentalni Mediciny), J. Hradec (General University Hospital), H. Skalicka (Poliklinika Praha 9).

\section{Denmark}

L. Kober (National Coordinator); PIs: J. Bronnumschou (H:S Amager Hospital), C. Torp-Pedersen (Bispebjerg Hospital).

\section{France}

Yves Juilliere (National Coordinator); PIs: G. Amat (Centre Hospitalier De Vichy), F. Bauer (Centre Hospitalier Universitaire Hopital Charles), J. Bouvier (Centre Hospitalier De Cholet), B. Charbonnier (C.H. Regional et Universitaire Hopital Trousseau), J. Demarcq (Hopital Victor Provo), R. Fouche (Centre Hospitalier Andre Boulloche), F. Funck (Centre Hospitalier Rene Dubos),

M. Genest (Centre Hospitalier Leon Binet), Yves Juilliere (Hospital Brabois Adultes), J. Kahn (C.H. Intercommunal De Poissy - Saint Germain en Laye), R. Ketelers (Clinique Du Bois), M. Komajda (Groupe Hospitalier Pitie-Salpetriere), M. Martelet (Centre Hospitalier De Langres), T. Olive (Centre Hospitalier De Gap), J. Poulard (Centre Hospitalier D'Abbeville), M. Richard (Centre Hospitalier General Hopital Broussais), J.L. Roynard (Centre Hospitalier De Dax).

\section{Germany}

R. Dietz (National Coordinator); PIs: C. Angermann (Klinikum Der Universitaet Wuerzburg), M. Boehm (Universitätskliniken Des Saarlandes), H. Figulla (Klinikum Der Friedrich-Schiller-Universität Jena), F. Freytag (Kreiskrankenhaus Gunzenhausen), L. Goedel-Meinen (Deutsches Herzzentrum), J. Hein (Praxis Dr. Jasper Hein), C. Hengstenberg (Klinikum Der Universitaet Regensburg), T. Horacek (Evangelisches Krankenhaus), J. Monti (FranzVolhard-Klinik Berlin), T, Muenzel (Klinikum Der Johannes-Gutenberg-Universitaet), B. Pieske (Klinikum Der Georg-August Universitaet), H. Olbrich (Asklepios Kliniken Langen-Seligenstadt), M. Rachor (Städtisches Krankenhaus Bad Homburg), H. Schultheiss (Universitätsklinikum Benjamin-Franklin), U. Sechtem (Robert-Bosch-Krankenhaus Stuttgart), H. Stahl (Stahl, Hans-Detlev), K. Stangl (Universitaetsklinikum Charite), H. Stempfle (Medizinische Klinik Innenstadt), R. Willenbrock (Krankenhaus St. Elisabeth Und St. Barbara), J. Wunderlich (Kardiologische Gemeinschaftspraxis).

\section{Greece}

D. Cokkinos (National Coordinator); PIs: D. Alexopoulos (University Hospital Of Patras), F. Kardaras (Evagelismos Hospital), D. Kremastinos (Onassis Cardiac Surgery Centre), I. Nanas (Alexandra University Hospital).

\section{Hungary}

I. Edes (National Coordinator); PIs: T. Buza (Budagyongye Hospital), I. Edes (Debrecen University), T. Forster (Szeged University), K. Simon (Siofok Varosi Korhaz).

\section{Ireland}

K. McDonald (National Coordinator); PI: V. Maher (Adelaide And Meath Hospital), K. McDonald (St. Vincent's Hospital).

\section{Italy}

L. Tavazzi (National Coordinator); PIs: E. Bernobich (Ospedale Cattinara - Univ.Trieste), D. Cucinotta (Azienda Ospedaliera Policlinico S.Orsola M.Malpighi), E. Feraco (I.N.R.C.A. Divisione Cardiologia), P. Fioretti (Ospedale Santa Maria Della Misericordia), L. Moretti (Ospedale Mazzoni), R. Nami (Policlinico Le Scotte-Ist.Clin. Med.Iii-U.O. Ipertensione), C. Prati (Azienda Unita' Sanitaria Locale Piacenza), R. Rozzini (U.O. Geriatria - Osp.Nuova Poliambulanza), U. Senin (Policlinico S.Maria Della Misericordia - U.O. Geriatria), L. Tavazzi (Ircss Policlinico S. Matteo -Divisione Di Cardiologia), M. Volpe (Az.Osp.S’Andrea / Dip.To Med.Sperimentale).

\section{Mexico}

C. Diaz (National Coordinator); PIs: C. Calvo (Hospital Civil Juan I. Menchaca), A. Cruz (Hospital Norte De Pemex), E. Gomez (Centro Medico Nacional 20 De Noviembre Issste), I. Hernandez (Hospital Juarez De Mexico), E. Meaney (Hospital Regional 1ero De Octubre Issste), A. Orea (Instituto Nacional De Ciencias Medicas Y Nutricion S.Z.), M. Rosas (Instituto Nacional De Cardiologia), C. Sanchez (Hospital De Enf. Cardiovasculares Y Del Torax \#34 Imss), E. Villegas (Central Medico Quirurgica De Aguascalientes).

\section{The Netherlands}

J. Cornel (National Coordinator); PIs: P. Bronzwaer (De Heel Zaans Medisch Centrum), J. Cornel (Medisch Centrum Alkmaar), L. Cozijnsen (Gelre Ziekenhuizen, Locatie Juliana), M. De Leeuw (Wilhelmina Ziekenhuis), A. Derks (Streekziekenhuis Midden-Twente), D. De Waard (Antonius Ziekenhuis), P. Dunselman (Amphia Ziekenhuis, Lokatie Molengracht), M. Freericks (Ikazia Ziekenhuis), B. Hamer (Meander Medisch Centrum, Lokatie Lichtenberg), D. Hertzberger (Canisius Wilhelmina Ziekenhuis), M. Nagelsmit (Scheper Ziekenhuis), P. Nierop (Sint Franciscus Gasthuis), J. Posma (Martini Ziekenhuis Lokatie Van Swieten), 
L. Slegers (Sint Joseph Ziekenhuis), F. Van Asperdt (Elkerliek Ziekenhuis, Lokatie Helmond), M. Van Daele (Maaslandziekenhuis), M.Van Der Linden (Vlietland Ziekenhuis Vlaardingen), P. Van Rossum (Rivas Medizorg), D. Van Veldhuisen (UMCG, Universitair Medisch Centrum Groningen), J. Verheul (Flevoziekenhuis), J. Wesdorp (Spaarne Ziekenhuis), A. Withagen (Reinier De Graaf Groep Delft).

\section{Norway}

J. Otterstad (National Coordinator); PIs: E. Aaser (Baerum Hospital), J. Otterstad (Vestfold Central Hospital), C. Von Brandis (Sentralsjukehuset I Rogaland).

\section{Poland}

P. Ponikowski (National Coordinator); PIs: M. Dluzniewski (Wojewodzki Szpital Brodnowski), Z. Gaciong (Klinika Nadcisnienia Tetniczego Akademii Medycznej), Z. Kubica (Akademia Medyczna Im. L. Rydygiera), M. Ogorek (Samodzielny Szpital Wojewodzki), P. Ponikowski (Szpital Wojskowy), W. Ruzyllo (Instytut Kardiologii), M. Tendera (Slaska Akademia Medyczna), M. Ujda (Powiatowy Szpital Specjalistyczny), B. Zalska (Zoz Mswia).

\section{Portugal}

R. Gomes (National Coordinator); PIs: D. Brito (Hospital De Santa Maria), M. Cortez (Hospital Pedro Hispano), C. Fonseca (Hospital Sao Francisco Xavier).

\section{Russia}

V. Mareev (National Coordinator); PIs: O. Alexandrov (Russian State Medical University), V. Ardashev (Central Military Clinical Hospital Burdenko), B. Bart (Russian State Medical University), S.I. Bogoslovskaya (Saratov Scientific Research Institute Of Cardiology), I. Bokarev (Municipal Clinical Hospital \# 20), S. Fitilev (City Cardiology Prophylactic Center), I. Fomina (Municipal Clinical Hospital \#61), M. Glezer (Municipal Clinical Hospital \# 59), B. Goloschekin (St. Petersburg City Hospital \# 15), E. Grineva (St. Petersburg State Medical University), A. Ivleva (Outpatient Clinic \#1), V. Kostenko (St. Petersburg Emergency Research Institute), V. Mareev (Moscow Cardiology Research Center), V. Milyagin (Smolensk State Medical Academy Of Ministry Of Public Health), S. Minkin (Consultative And Diagnostic Center \# 1), N. Nosova (St. Petersburg Outpatient Clinic \# 34), L.I. Olbinskaya (Moscow Medical Academy), V. Orlov (Medical Academy Of Postgraduate Ed.), N. Perepetch (Mechnikov Medical Academy), M. Repin (St. Petersburg City Outpatient Clinic \# 40), M. Ruda (Moscow Cardiology Research Center), A. Sherenkov (Krasnogvardeysky District MedicalPhysiology), E. Shlyakhto (St. Petersburg Cardiology Research Institute), B. Sidorenko (Govermental Central Clinical Hospital), A. Sinopalnikov (Institute Of Postgraduate Medical Education Of Dm), A. Starodubtsev (Municipal Clinical Hospital \# 23 Named After Medsantrud), G. Storozhakov (Russian State Medical University), Y. Vasyuk
(Moscow Medical Stomatological Institute), A. Vishnevsky (St. Petersburg City Pokrovskaya Hospital), G. Zalevsky (St. Petersburg Municipal Clinical Hospital \# 28), D. Zateystchikov (Municipal Clinical Hospital \# 51).

\section{South Africa}

A. Dalby (National Coordinator); PIs: A. Dalby (Milpark Hospital), C. Libhaber (Chris Hani Baragwanath Hospital), D. Naidoo (Nelson R. Mandela School Of Med), J. Patel (St. Augustine's Medical Centre 2), L. Steingo (Morningside Clinic).

\section{Spain}

J. Gonzalez-Juanatey (National Coordinator); PIs: M. Anguita Sanchez (Hospital Universitario Reina Sofia), C. Calvo Gomez (Hospital Clinico Univ. De Santiago De C.), J. Casademont (Hospital Clinic), P. Conthe (Hospital Gral. Univ. Gregorio Maranon), E. De Teresa Galvan (Hospital Univ. Virgen De La Victoria), J. M. Fernandez (Hospital Universitario Virgen Macarena), I. Ferreira (Hospital Clinico Univ. Lozano Blesa), J. Forteza (Hospital Son Dureta), J. Garcia Puig (Hospital Universitario La Paz), J. Gonzalez-Juanatey (Hospital Clinico Univ. De Santiago De C.), L. Pastor (Hospital Universitario De Valme), F. Ridocci-Soriano (Hospital General Univ. De Valencia), F. Soria (Hospital Univ. Virgen De La Arrixaca), C. Suarez (Hospital Universitario De La Princesa), J. Zamorano (Hospital Clinico San Carlos).

\section{Sweden}

U. Dahlstrom (National Coordinator); PIs: G. Ahlmark (Falun Hospital), K. Boman (Skelleftea County Hospital), U. Dahlstrom (Linkoping University Hospital), C. Hoglund (City Heart Stockholm Kb), T. Kahan (Danderyd Hospital), M. Lycksell (Sundsvall County Hospital), M. Schaufelberger (Sahlgrenska University Hospital/Ostra), R. Willenheimer (University Hospital Mas).

\section{Switzerland}

F. Follath (National Coordinator); PI: A. Gallino (Gallino Augusto), W. Estlinbaum (Kantonsspital).

\section{U.K.}

T. McDonagh (National Coordinator); PIs: J. Cleland (Hull Royal Infirmary), J. McMurray (Western Infirmary), J. Purvis (Altnagelvin Area Hospital), M. Pye (York District Hospital), J. Stephens (Oldchurch Hospital).

\section{USA}

National Coordinators: D. Kitzman, C. O’Connor.

\section{Alabama}

A. Bouchard (Cardiology P.C.). 


\section{Arizona}

M. Goldberg (Saguaro Clinical Research), S. Goldman (Southern Arizona VA Health Care System), B. Peart (Southwest Heart), G. Wong (Cardiac Solutions).

\section{Arkansas}

Y. Aude (Cent. Arkansas Vet Health Sys.).

\section{California}

R. Davidson (Capri), B. Greenberg (UCSD Medical Center), B. Massie (San Francisco Veterans Affairs Medical Center).

\section{Connecticut}

W. D. Hagar (UConn Health Center).

\section{Florida}

K. Adams (Jacksonville Heart Center), L. Hendley (Benchmark Clin Mangt Group), T. Hilton (Jacksonville Heart Center), M. Lakow (Florida CV Research, L.C.), R. Schneider (The Broward Heart Group, PA), D. Schocken (University Of South Florida-College Of Medicine).

\section{Illinois}

B. Clemson (Heartcare Midwest).

\section{Indiana}

J. Ortiz (Research Institute Of Middle America).

\section{Kentucky}

M. Bessen (MCC Research Foundation).

\section{Louisiana}

J. Ghali (Louisiana State University Health Sciences Center-Shreveport), B. Iteld (Louisiana Heart Center).

\section{Maine}

R. Weiss (Androscoggin Cardio. Assoc.).

\section{Maryland}

R. DiBianco (Cardiovascular Consultants), S. Mason (Midatlantic Cardiovascular Associates), J. Porterfield (Midatlantic Cardiovascular Associates, PA).

\section{Massachusetts}

S. Bilazerian (Pentucket Medical Associates), M. Semigran (Massachusetts General Hospital), V. Desai (Charles River Medical Associates).

\section{Michigan}

H. Colfer (Northern Michigan Hospital), M. Guglin (John D Dingell VAMC).

\section{Minnesota}

I. Anand (Univ. of Minnesota Medical School).

\section{Missouri}

M. Rich (Washington University School Of Medicine).

\section{Nebraska}

D. Chapman (Heart Consultants, PC), A. Reyes (Creighton Cardiac Center).

\section{Nevada}

W. Graettinger (Reno VAMC).

New Jersey

M. Gelernt (Cardiovascular Associates Of The Delaware Valley).

\section{New Hampshire}

B. Hettleman (Dartmouth-Hitchcock Medical Center).

\section{New Mexico}

R. Orchard (New Mexico Heart Institute).

\section{New York}

L. Baruch (VA Medical Center), R. Benton (Capital Cardiology Associates, PC), C. Liang (University Of Rochester Medical Center), R. Silverman (Silverman Heart Care Center).

\section{North Carolina}

P. Campbell (North East Medical Center), D. Kitzman (Wake Forest University), C. O'Connor (Duke University Medical Center), C. Sueta (University Of North Carolina At Chapel Hill).

\section{Ohio}

P. Amsterdam (Cardiovascular Research Institute, Inc.), E. Chung (Lindner Clinical Trial Center), D. Grech (North Ohio Research Ltd.), M. Traboulssi (North Ohio Research, Ltd.), D. Utlak (United Health Network, Ltd.).

\section{Oregon}

S. Lewis (Northwest Cardiovascular Institute).

\section{Pennsylvania}

R. Rodriquez (Chestnut Hill Cardiology Ltd.), R. Small (Lancaster Heart Foundation).

\section{South Carolina}

T. O'Brien (Medical University Of South Carolina), M. Zile (Medical University Of South Carolina).

\section{Tennessee}

F. McGrew (Stern Cardiovascular Center, PA).

\section{Texas}

S. Blois (Austin Heart, PA Research Account). 


\section{Virginia}

R. Goulah (DUCCS Of South Boston), T. Nygaard (Cardiovascular Associates Of Central VA, Inc.), M. Peberdy (Virginia Commonwealth University).

\section{Washington}

D. Stagaman (Rockwood Clinic Cardiology @ Heart Institute).

\section{References}

1. American Heart Association. Heart Disease and Stroke Statistics-2004 update. Dallas (TX): American Heart Association; 2003.

2. Lapu-Bula R, Ofili E. Diastolic heart failure: the forgotten manifestation of hypertensive heart disease. Curr Hypertens Rep 2004;6:64-170.

3. Thomas MD, Fox KF, Coats AJ, Sutton GC. The epidemiological enigma of heart failure with preserved systolic function. Eur J Heart Fail 2004;6:125-36.

4. Hogg K, Swedberg K, McMurray J. Heart failure with preserved left ventricular systolic function; epidemiology, clinical characteristics, and prognosis. J Am Coll Cardiol 2004;43:317-27.

5. Vasan RS, Larson MG, Benjamin EJ, Evans JC, Reiss CK, Levy D. Congestive heart failure in subjects with normal versus reduced left ventricular ejection fraction: prevalence and mortality in a population-based cohort. J Am Coll Cardiol 1999;33:1948-55.

6. Kitzman DW, Gardin JM, Gottdiener JS, Arnold A, Boineau R, Aurigemma G, et al. Importance of heart failure with preserved systolic function in patients $>$ or $=65$ years of age. CHS Research Group. Cardiovascular Health Study. Am J Cardiol 2001;87:413-9.

7. Cleland JG, Swedberg K, Follath F, Komajda M, Cohen-Solal A, Aguilar JC, et al. The EuroHeart Failure survey programme-a survey on the quality of care among patients with heart failure in Europe. Part 1: patient characteristics and diagnosis. Eur Heart J 2003;24:442-63.

8. Fonarow GC. The Acute Decompensated Heart Failure National Registry (ADHERE): opportunities to improve care of patients hospitalized with acute decompensated heart failure. Rev Cardiovasc Med 2003;4(Suppl 7):S21-30.

9. Remme WJ, Swedberg K. Comprehensive guidelines for the diagnosis and treatment of chronic heart failure. Task force for the diagnosis and treatment of chronic heart failure of the European Society of Cardiology. Eur J Heart Fail 2002;4:11-22.

10. Yusuf S, Pfeffer MA, Swedberg K, Granger CB, Held P, McMurray JJ, et al. CHARM Investigators and Committees. Effects of candesartan in patients with chronic heart failure and preserved left-ventricular ejection fraction: the CHARM-Preserved Trial. Lancet 2003;362:777-81.

11. Zile MR, Gaasch WH, Carroll JD, Feldman MD, Aurigemma GP, Schaer GL, et al. Heart failure with a normal ejection fraction: is measurement of diastolic function necessary to make the diagnosis of diastolic heart failure? Circulation 2001;104:779-82.

12. Zile MR, Baicu CF, Gaasch WH. Diastolic heart failure-abnormalities in active relaxation and passive stiffness of the left ventricle. N Engl J Med 2004;350:1953-9.

13. Yamamoto K, Masuyama T, Sakata $\mathrm{Y}$, Mano $\mathrm{T}$, Nishikawa N, Kondo $\mathrm{H}$, et al. Roles of renin-angiotensin and endothelin systems in development of diastolic heart failure in hypertensive hearts. Cardiovasc Res 2000;47:274-83.

14. Schunkert H, Jackson B, Tang SS, Schoen FJ, Smits JF, Apstein CS, et al. Distribution and functional significance of cardiac angiotensin converting enzyme in hypertrophied rat hearts. Circulation 1993;87: 1328-39.

15. Schunkert H, Dzau VJ, Tang SS, Hirsch AT, Apstein CS, Lorell BH. Increased rat cardiac angiotensin converting enzyme activity and mRNA expression in pressure overload left ventricular hypertrophy. Effects on coronary resistance, contractility, and relaxation. J Clin Invest 1990;86:1913-20.

16. Carson PE, Johnson GR, Fletcher RD, Cohn JN for the V-HeFT Cooperative Studies Group. Mild systolic dysfunction heart failure (LVEF > 35\%): baseline characteristics, prognosis, response to therapy. J Am Coll Cardiol 1996;27:642-9.

17. Warner JG Jr, Metzger DC, Kitzman DW, Wesley DJ, Little WC. Losartan improves exercise tolerance in patients with diastolic dysfunction and a hypertensive response to exercise. J Am Coll Cardiol 1999; 33:1567-72.

18. Malmqvist K, Kahan T, Edner M, Held C, Hagg A, Lind L, et al. Regression of left ventricular hypertrophy in human hypertension with irbesartan. J Hypertens 2001;19:1167-76.

19. Berl T, Hunsicker LG, Lewis JB, Pfeffer MA, Porush JG, Rouleau JL, et al. Cardiovascular outcomes in the Irbesartan Diabetic Nephropathy Trial of patients with type 2 diabetes and overt nephropathy. Ann Intern Med 2003;138:542-9.

20. O'Connor CM, Gattis WA, Shaw L, Cuffe MS, Califf RM. Clinical characteristics and long-term outcome of patients with heart failure and preserved systolic function. Am J Card 2000;86:863-7.

21. Rich MW, Beckham V, Wittenberg C, Leven CL, Freedland KE, Carney RM. A multidisciplinary intervention to prevent the readmission of elderly patients with congestive heart failure. N Engl J Med 1995;333:1190-5.

22. Swedberg K, Pfeffer M, Granger C, Held P, McMurray J, Ohlin G, et al. Candesartan in heart failure-assessment of reduction in mortality and morbidity (CHARM): rationale and design. Charm-Programme Investigators. J Card Fail 1999;5:276-82.

23. The Digitalis Investigation Group. The effect of digoxin on mortality and morbidity in patients with heart failure. N Engl J Med 1997;336: $525-33$.

24. Latini R, Masson S, Anand I, Judd D, Maggioni AP, Chiang Y-T, et al. for the Val-HeFT Investigators. Effects of valsartan on circulating brain natriuretic peptide and norepinephrine in symptomatic chronic heart failure: The Valsartan Heart Failure Trial (Val-HeFT). Circulation 2002;106:2454-8. 